
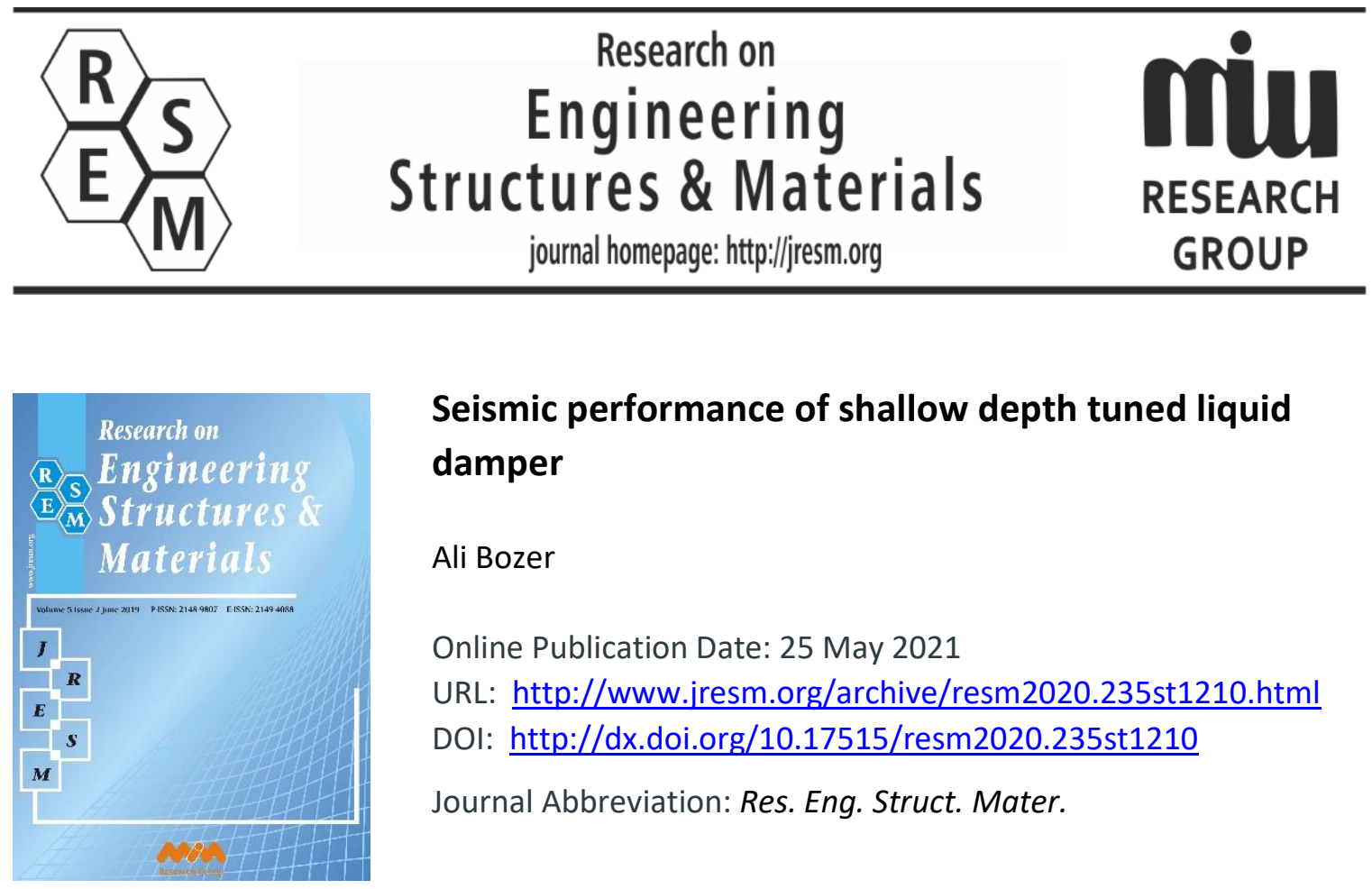

\title{
Seismic performance of shallow depth tuned liquid damper
}

Ali Bozer

Online Publication Date: 25 May 2021

URL: http://www.jresm.org/archive/resm2020.235st1210.html

DOI: http://dx.doi.org/10.17515/resm2020.235st1210

Journal Abbreviation: Res. Eng. Struct. Mater.

\section{To cite this article}

Bozer A. A Seismic performance of shallow depth tuned liquid damper. Res. Eng. Struct. Mater., 2021; 7(3) 431-444.

\section{Disclaimer}

All the opinions and statements expressed in the papers are on the responsibility of author(s) and are not to be regarded as those of the journal of Research on Engineering Structures and Materials (RESM) organization or related parties. The publishers make no warranty, explicit or implied, or make any representation with respect to the contents of any article will be complete or accurate or up to date. The accuracy of any instructions, equations, or other information should be independently verified. The publisher and related parties shall not be liable for any loss, actions, claims, proceedings, demand or costs or damages whatsoever or howsoever caused arising directly or indirectly in connection with use of the information given in the journal or related means.

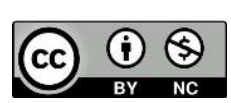

Published articles are freely available to users under the terms of Creative Commons Attribution - NonCommercial 4.0 International Public License, as currently displayed at here (the "CC BY - NC"). 


\section{Research on Engineering Structures \& Materials}

journal homepage: http://jresm.org

Research Article

\section{Seismic performance of shallow depth tuned liquid damper}

\section{Ali Bozer}

Department of Civil Engineering, Nuh Naci Yazgan University, Kayseri, Turkey

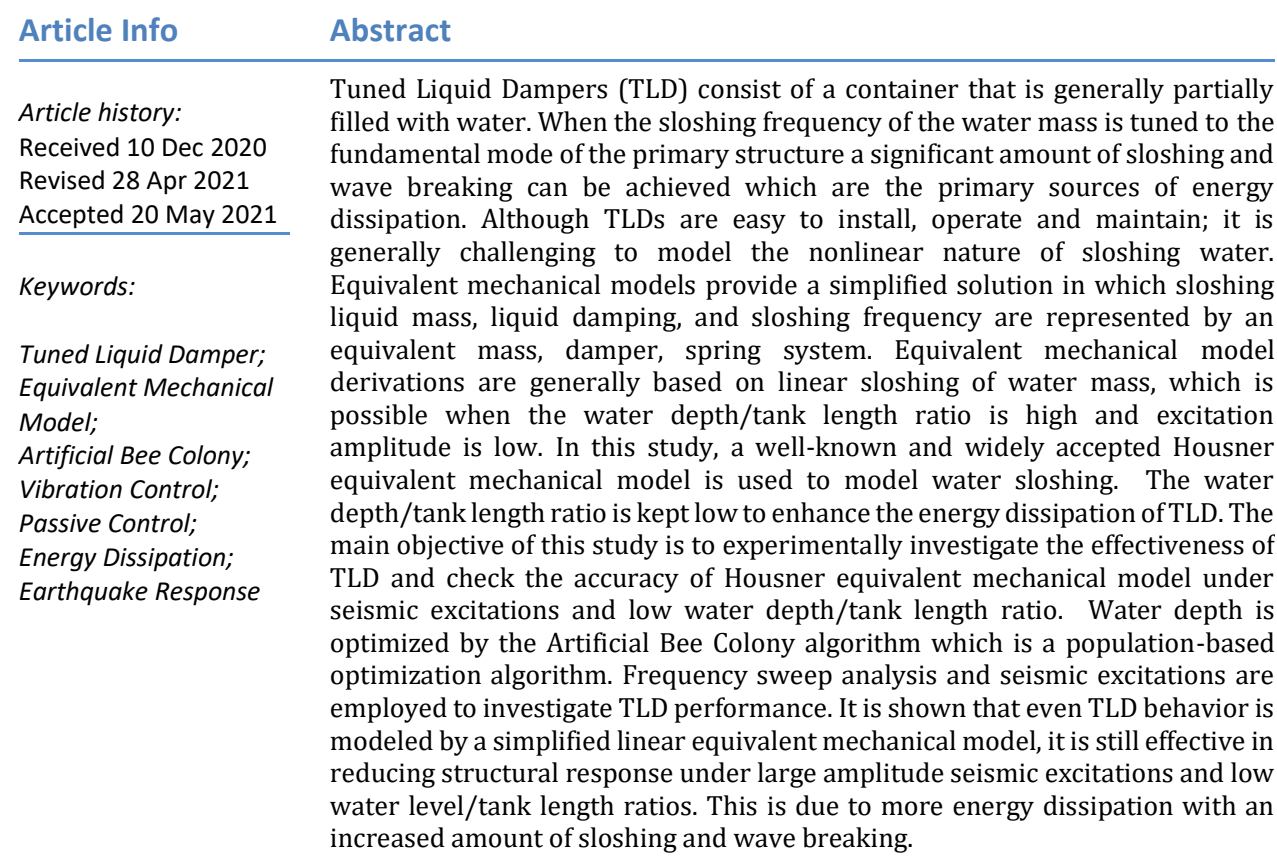

(C) 2021 MIM Research Group. All rights reserved.

\section{Introduction}

Tuned-mass dampers (TMDs) are mass-spring systems where a moving auxiliary mass is attached to the primary structure. Auxiliary mass induces dynamic forces opposing the motion of the primary structure when the natural frequency of TMD is tuned to the fundamental mode of the primary structure. Tuned Mass Dampers are the origin of Tuned Liquid Dampers (TLDs) in which auxiliary mass is the sloshing of a liquid (usually water) mass contained either with a rectangular or circular tank. Lateral sloshing is the wave formation on the surface of a liquid when a tank partially filled with liquid oscillates. When a fluid container is subjected to horizontal accelerations, the free liquid surface moves up at one side of the container and moves down at the other forming a wave. Liquid sloshing frequency is a function of tank dimensions and liquid depth, thus it is easy to adjust the natural frequency of the TLD unit. By doing so any vibrational mode of the primary structure can be controlled, and possible variations in the dominant mode of the primary structure can easily be adapted. 
The idea of using TLD in civil engineering applications is first introduced by Bauer [1] and until that time the performance of TLD under seismic and wind excitations are investigated by many researchers [2-12].

Owing to their low maintenance requirement, cost-effectiveness, and ease of installation, TLDs attracted considerable attention in civil engineering applications. One important drawback on the other hand is the low inherent damping ratio of the sloshing liquid. The damping ratio of water is given as $0.5 \%$ in Eurocode 8 [14]. Özsarıyıldız and Bozer [15] utilized a differential evolution algorithm to obtain optimum parameters of TMD. Optimal damping ratios reported in their paper are far more than the natural damping ratio of linear sloshing water. Therefore lesser control performance is expected with TLD when compared to the TMD case.

When a TLD is subjected to motion with large amplitudes as expected in strong earthquake ground motions, wave breaking and shearing of the fluid is the primary form of mechanical damping, providing that the liquid level is low [4]. At this point, simple linear models can no longer describe the liquid behavior, and wave breaking changes the sloshing frequency of the liquid [8]. From a set of numerical simulations, Banerji et al. [9] showed that a low water depth/tank length ratio of 0.15 for a TLD, is more effective for large excitation amplitudes. Mars et al. [13] concluded that for shallow liquid levels traveling waves are generated whereas as the liquid level increases a transition to standing waves occurs. Energy dissipation in a sloshing liquid is mainly due to wave-to-wave and wave-to-wall interactions. Traveling waves can produce both interactions, whereas standing waves only produce wave-to-wall interactions.

The primary difficulties associated with the design of TLDs arise from the nonlinear nature of the sloshing fluid. Numerous fluid models have been proposed in the literature to describe sloshing, each of which is based upon simplifying assumptions that are valid for certain types of sloshing problems. The validity of many fluid models is dependent on the mean fluid depth to tank length ratio [16]. However complex nature of these models and necessary computational effort made these models impractical for TLD design. A simplified model was introduced by Housner [17] in which the sloshing liquid is represented by an equivalent mass, spring, and dashpot system. Whereas this equivalent model is derived for linear oscillations of liquid mass which is valid for small amplitude excitations and high (more than 0.20 ) liquid depth/tank length ratios.

In this study, a shallow depth TLD where water depth/tank length ratio kept below 0.15 is used to control seismic vibrations. Housner's [17] equivalent mechanical model is used to represent sloshing water in a rectangular tank. Housner's [17] equivalent model is valid for small liquid displacements where linear sloshing is expected. For shallow liquid levels and high amplitude excitations, on the other hand, nonlinear sloshing is likely to occur. However, the equivalent mechanical model is a simple tool and might be a good starting point for obtaining optimal TLD parameters. The main objective of this study is to experimentally investigate the effectiveness of TLD and check the accuracy of the Housner's [17] equivalent mechanical model when large amplitude vibrations and low water depth/tank length ratios present. The optimal water depth is obtained by Artificial Bee Colony (ABC) Algorithm [18] which is a population-based optimization algorithm. As to the best knowledge of authors, $\mathrm{ABC}$ Algorithm is first used in Finding Optimal Parameters of Tuned Liquid Dampers. The frequency-domain response is obtained by a frequency sweep analysis where large amplitude sinusoidal ground excitations are employed via a shaking table. The seismic performance of the tuned liquid damper is further investigated under seismic excitations. 


\section{Numerical Model}

\subsection{Equivalent Mechanical Model}

The solution of the sloshing problem necessitates solving of some partial differential equations satisfying boundary conditions, however; Housner [17] presented an approximate method that avoids partial differential equations and presents solutions for several cases (rectangular tank, circular tank, elliptical tank) in simple closed form. Simplified formulas are given to estimate hydrodynamic pressures when a fluid container is subjected to horizontal accelerations. The essence of the method is the estimation of a simple type of flow that is similar to the actual fluid movement and this simple flow is used to determine the pressure. Basic assumptions for this method are a) fluid is incompressible b) fluid displacements are small c) fluid is constrained between rigid membranes and free to rotate.

If a tank with a free water surface is subjected to horizontal ground acceleration, a certain fraction of water is forced to participate in the back and forth motion of the tank which exerts an impulsive force on the tank. Impulsive force is equal to the inertia force of a rigidly attached mass M0 subjected to tank acceleration. Furthermore, the motion of the tank walls excites the water into oscillations which in turn exert an oscillating force on the tank. The oscillating force is equal to the oscillating mass M1 that is attached to a restraining spring. The mass M1 corresponds to the fundamental mode of oscillation of water.

For a rectangular container with a length $\mathrm{L}$, fluid depth $\mathrm{h}$ and acceleration of the gravity g; stationary fluid mass M0, oscillating fluid mass M1 and natural sloshing frequency $\omega$ is given by the following equations:

$$
\begin{aligned}
\mathrm{M}_{0} & =\mathrm{M} \frac{\tanh (\sqrt{3} \mathrm{~L} / 2 \mathrm{~h})}{\sqrt{3} \mathrm{~L} / 2 \mathrm{~h}} \\
\mathrm{M}_{1} & =\mathrm{M} \frac{1}{3} \sqrt{\frac{5}{2}} \frac{\mathrm{L}}{2 \mathrm{~h}} \tanh \left(\sqrt{\frac{5}{2}} \frac{2 \mathrm{~h}}{\mathrm{~L}}\right) \\
\omega^{2} & =\frac{2 \mathrm{~g}}{\mathrm{~L}} \sqrt{\frac{5}{2}} \tanh \left(\sqrt{\frac{5}{2}} \frac{2 \mathrm{~h}}{\mathrm{~L}}\right)
\end{aligned}
$$

Once the above equations are obtained, equivalent spring stiffness kd can be computed from:

$$
k_{d}=\omega^{2} M_{1}
$$

\subsection{TLD-Structure Interaction Model}

Considering an n-story MDOF linear building structure with a mass damper installed at the top floor, the equation of motion of the combined system subjected to ground acceleration can be written as:

$$
\boldsymbol{M} \ddot{\boldsymbol{X}}(t)+\boldsymbol{C} \dot{\boldsymbol{X}}(t)+\boldsymbol{K} \boldsymbol{X}(t)=-\boldsymbol{m} \ddot{x}_{g}(t)
$$

where $\mathbf{X}$ is the $(\mathrm{n}+1)$-dimensional response vector denoting the relative displacement with respect to the ground; $\ddot{x}_{g}$ is the ground acceleration; $\mathbf{M}, \mathbf{C}$, and $\mathbf{K}$ are $(n+1 \times n+1)$ dimensional positive-definite matrices corresponding to the mass, viscous damping, and the stiffness of the structure, respectively. More specifically they can be written as follows: 


$$
\begin{aligned}
& \boldsymbol{m}=\left[\mathrm{m}_{1}, \mathrm{~m}_{2}, \ldots, \mathrm{m}_{\mathrm{n}}, \mathrm{m}_{\mathrm{d}}\right]^{\mathrm{T}} \\
& \mathbf{X}(\mathrm{t})=\left[\mathrm{x}_{1}, \mathrm{x}_{2}, \ldots, \mathrm{x}_{\mathrm{N}}, \mathrm{x}_{\mathrm{d}}\right]^{\mathrm{T}}
\end{aligned}
$$

$\mathbf{M}=\left[\begin{array}{cccccc}\mathrm{m}_{1} & & & & & \\ & \mathrm{~m}_{2} & & 0 & \\ & & \cdot & & & \\ & 0 & & \mathrm{~m}_{\mathrm{n}} & \\ & & & & \mathrm{m}_{\mathrm{d}}\end{array}\right]$

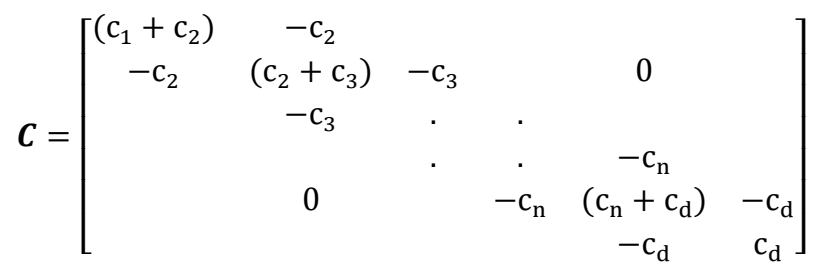

$$
\boldsymbol{K}=\left[\begin{array}{cccccc}
\left(k_{1}+k_{2}\right) & -k_{2} & & & & \\
-k_{2} & \left(k_{2}+k_{3}\right) & -k_{3} & & 0 & \\
& -k_{3} & \cdot & \cdot & & \\
& & \cdot & \cdot & -k_{n} & \\
& 0 & & -k_{n} & \left(k_{n}+k_{d}\right) & -k_{d} \\
& & & & -k_{d} & k_{d}
\end{array}\right]
$$

where, $\mathrm{mi}$ is the mass of $\mathrm{i}$ th floor; md is the mass of the damper; ci is the damping of the $i$ th floor; cd is the damping of the damper; ki is the stiffness of $i$ th floor; kd is the stiffness of the damper; $x i$ is the displacement of $i$ th floor relative to ground; $x d$ is the displacement of the damper relative to ground. The equation of motion can then be converted to a statespace equation as:

$$
\dot{Z}=\boldsymbol{A Z}+\boldsymbol{H} \ddot{x}_{g}(t)
$$

Where

$$
\boldsymbol{Z}(t)=\left[\begin{array}{c}
\boldsymbol{X}(t) \\
\dot{\boldsymbol{X}}(t)
\end{array}\right] ; \boldsymbol{A}=\left[\begin{array}{cc}
\mathbf{0} & \boldsymbol{I} \\
-\boldsymbol{M}^{-\mathbf{1}} \boldsymbol{K} & -\boldsymbol{M}^{-\mathbf{1}} \boldsymbol{C}
\end{array}\right] ; \boldsymbol{H}=\left[\begin{array}{c}
\mathbf{0} \\
\boldsymbol{M}^{-\mathbf{1}} \boldsymbol{m}
\end{array}\right]
$$

By transforming the equation of motion to the state space equation, the second-order differential equation is transformed to the first-order one. In this case, the transfer function is given by:

$$
\boldsymbol{G}(i \omega)=\boldsymbol{C}_{\boldsymbol{y}}(i \omega \boldsymbol{I}-\boldsymbol{A})^{-1} \boldsymbol{H}
$$

where $\mathbf{C}_{\mathbf{y}}$ is the $2 \mathrm{x}(\mathrm{n}+1)$-dimensional output matrix; $\mathbf{I}$ is the identity matrix and $\omega$ is the circular frequency argument.

\subsection{ABC Optimization Algorithm}

In this study, Artificial Bee Colony (ABC) optimization algorithm [18] is used to find optimal parameters of the TLD system. ABC algorithm is a swarm-based meta-heuristic optimization algorithm inspired by the intelligent foraging behavior of honey bees. $A B C$ is 
utilized in the optimization of Multiple Tuned Mass Dampers and proved to be powerful enough to handle a large number of design variables [19].

In $\mathrm{ABC}$, a colony of artificial forager bees (agents) searches for rich artificial food sources (good solutions for a given problem). The colony contains three groups of bees: employed bees associated with specific food sources, onlooker bees watching the dance of employed bees within the hive to choose a food source, and scout bees searching for food sources randomly [20].

In the initial stage, scout bees discover all food source positions. Each food source xi,j is a solution vector to the optimization problem and the nectar amount of a food source corresponds to the quality (fitness) of the associated solution.

$$
x_{i, j}=x_{j}^{\min }+\operatorname{rand}(0,1)\left(x_{j}^{\max }-x_{j}^{\min }\right)
$$

where $\mathrm{i}=1 . \mathrm{SN}$, and $\mathrm{j}=1$..D. SN indicates the number of solutions and the number of parameters is presented as D.

In the employed bee stage, employed bees search for new food sources. They find a neighbor food source vi and then assess its fitness by the function given in Eq. 15.

$$
v_{i, j}=x_{i, j}+\emptyset_{i j}\left(x_{j, j}-x_{k, j}\right)
$$

where $\mathrm{x}_{\mathrm{k}}$ is a randomly selected food source, $\mathrm{j}$ is a random index number within the limits of $[1, D], \emptyset_{i, j}$ is a uniformly distributed random number in the range $[-1,1]$. The fitness value of the solution is calculated by:

$$
\text { fitness }_{i}=f(x)=\left\{1+\operatorname{abs}\left(f_{i}\right), \quad \text { if } x<01 /\left(1-f_{i}\right), \quad \text { if } x \geq 0\right.
$$

where $f_{i}$ is the cost function to a given the solution vi. Employed bees share their food source information with onlooker bees waiting in the hive and depending on this information, onlooker bees probabilistically choose their food sources based on the roulette wheel selection method. The probability value is calculated by:

$$
p_{i}=\text { fitness }_{i} / \sum_{i=1}^{S N} \text { fitness }_{i}
$$

Once the onlooker bees probabilistically chose a food source $\mathrm{x}_{\mathrm{i}}$, a neighboring food source $\mathrm{V}_{\mathrm{i}}$ is determined and its fitness value is calculated. Employed bees whose solutions cannot be improved through a predetermined number of trials become scouts. The converted scouts start to search for new solutions, randomly.

In this study tank dimensions are kept fixed, thus water depth is the optimization parameter. For a possible water depth and fixed tank dimensions, a total water mass is obtained. Through Eqs. (1)-(4) stationary fluid mass $\mathrm{M}_{0}$, oscillating fluid mass $\mathrm{M}_{1}$, natural sloshing frequency $\omega$, and equivalent spring stiffness $k_{d}$ are calculated. Then mass, damping, and stiffness matrices are calculated by Eqs. (8)-(10). The state-space equation is then constructed by Eq. (12) and the transfer function is obtained by Eq. (13). The best possible solution is obtained by minimizing $\mathrm{H} 2$ norm of the transfer function. It is possible to adjust TLD mass/structure mass ratio by just varying tank width which does not affect sloshing frequency. 


\section{Experimental Setup}

\subsection{Shake Table}

Servo motor driven small-scale shake table used in this study has a $50 \mathrm{~kg}$ work capacity and is capable of producing $\pm 2 \mathrm{~g}$ acceleration in one horizontal axis. The embedded PID controller makes it possible to simulate sinusoidal motions, real earthquake motions, and user-controlled movements (arbitrary waveforms). Roof displacements are measured via a laser displacement sensor.

\subsection{Test Structure and System Matrices}

The test structure is made of two steel plate walls connected with a steel plate deck on roof level (Fig. 1. a). Plate wall height is $140 \mathrm{~cm}$, length is $35 \mathrm{~cm}$, and thickness is $0.29 \mathrm{~cm}$. Plate deck dimensions are $35 \times 35 \mathrm{~cm}$, and thickness is $1 \mathrm{~cm}$ which provides the structure mass. According to free vibration analysis, the fundamental period of the structure is $0.82 \mathrm{sec}$ $(1.234 \mathrm{~Hz})$ and the damping ratio calculated is $2 \%$ according to the logarithmic decrement method as described by Chopra [21].

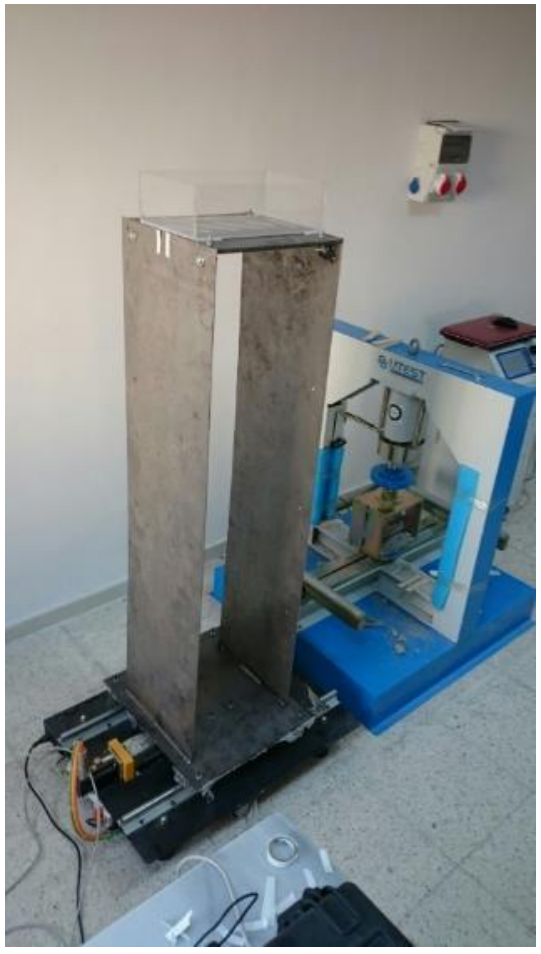

(a)
X.: Deformed Shape (MODAL) - Mode 1; $\mathrm{T}=0,82048 ; \mathrm{f}=1,21879$

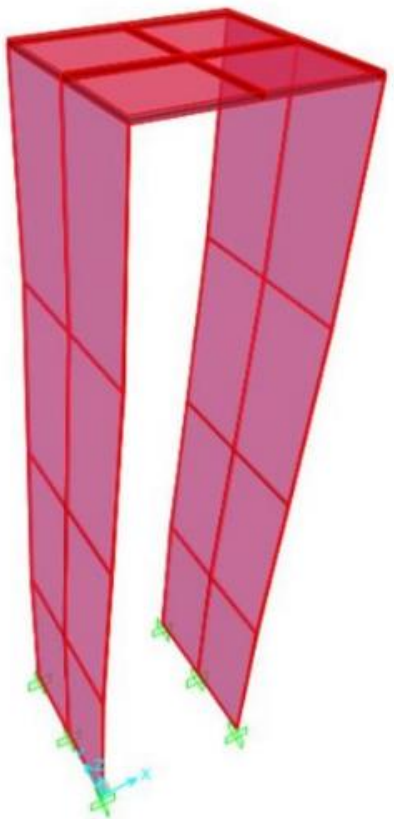

(b)

Fig. 1 a) Test Structure b) 1. Modal Shape of Numerical Model

The numerical model of the test structure is constructed with SAP 2000 [22]. Plate walls and roof deck are modeled with shell elements. Rigid connection is assumed between plate walls and base plate, between plate walls and roof deck (Fig. 1 b). The estimated fundamental period is $0.72 \mathrm{sec}$ in this case which indicates the rigid connection assumption is not truly valid. Thus Elasticity Modulus of steel is calibrated to match the fundamental periods of the numerical model and experimental findings. The mass, stiffness, and damping matrices of the calibrated model are given as: 


$$
\begin{aligned}
\boldsymbol{M} & =\operatorname{diag}[5.5764,5.5764,5.5764,12.404] * 10^{-3} \text { ton } \\
\boldsymbol{K} & =\left[\begin{array}{cccc}
105.59 & -67.87 & 29.10 & -7.27 \\
-67.87 & 84.84 & -67.77 & 25.35 \\
29.10 & -67.77 & 106.03 & -60.08 \\
-7.27 & 25.35 & -60.08 & 40.17
\end{array}\right] \mathrm{kN} / \mathrm{m} \\
\boldsymbol{C} & =\alpha M+\beta K
\end{aligned}
$$

$\alpha$ and $\beta$ are Rayleigh coefficients and are calculated as $\alpha=0.2656$ and $\beta=6.94 * 10^{-4}$ for damping ratio $\% 2$ of first and second vibration periods of the structure.

\subsection{Optimal TLD Parameters}

A fiberglass tank with a length of $25 \mathrm{~cm}$ and a width of $20 \mathrm{~cm}$ is used as a TLD unit. The calculated optimal water depth is $3.1 \mathrm{~cm}$ which corresponds to the 0.12 water depth/tank length ratio. In this case, calculated stationary fluid mass, $M_{0}$ is $0.22 \mathrm{~kg}$, oscillating fluid mass $\mathrm{M}_{1}$ is $1.23 \mathrm{~kg}$ which corresponds to $4.1 \%$ of the total structural mass, and natural sloshing frequency $\omega$ is $0.92 \mathrm{~Hz}(1.087 \mathrm{sec})$.

\section{Experimental Findings}

\subsection{Frequency Sweep Analysis}

Frequency sweeps are conducted, in which the structure is excited at 17 discrete frequencies in the range of 0.8 to 1.2 times of fundamental structural frequency at a constant displacement amplitude. The system is excited for 10 cycles with an amplitude of $10 \mathrm{~mm}$, and data is recorded until a steady-state condition is attained. A total of two frequency sweep tests are conducted which consider the structure with TLD (controlled) and without TLD (uncontrolled) settings.

Frequency response curves of both controlled and uncontrolled structures are constructed to show the roof displacement at each excitation frequency (Fig. 2). The roof displacement and excitation frequency are normalized by the maximum roof displacement and the fundamental natural frequency of the uncontrolled structure respectively.

Roof displacement time history plots are given in Figs. 3-5 for excitation frequencies of 0.8, 1 , and 1.2 times the fundamental frequency of the uncontrolled structure respectively.

It should be noted from Fig. 2 that there is a slight shift $(-2.5 \%)$ in the resonance frequency of the uncontrolled structure concerning the natural frequency identified from free vibration results. This is probably due to the loosening of connection bolts at $13 \%$ roof drift demands corresponding to the resonance frequency. It is observed that when a structure is equipped with TLD, additional water mass present in the water tank causes a further $5 \%$ frequency shift in the first mode frequency concerning uncontrolled structure.

When normalized roof displacements are considered, maximum efficiency is obtained when the structure is excited with a resonant frequency. In this case reduction in max roof displacement of the controlled structure is $55 \%$ with respect to uncontrolled structure. The primary means of energy dissipation seem to be strong wave breaking and wave-towall interactions. Displacement peaks take place at different frequencies for controlled and uncontrolled structures. Thus, when the entire frequency range is considered, the reduction in max roof displacement of the controlled structure is $37 \%$ with respect to uncontrolled structure. 


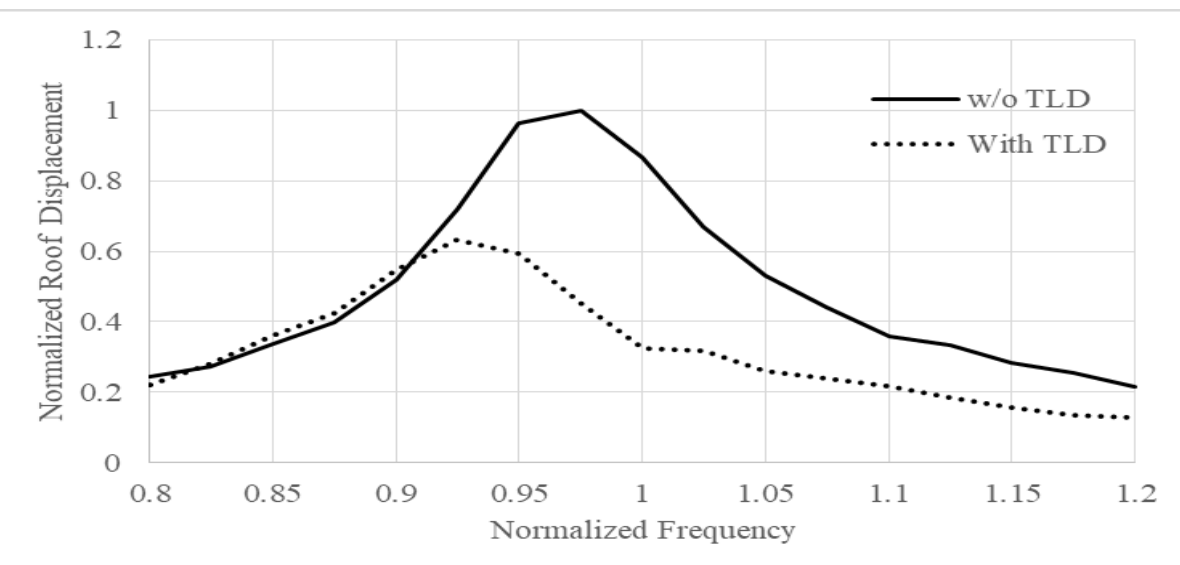

Fig. 2 Frequency Response Curves of Structure With and Without TLD Settings

At a normalized frequency range of 0.8 to 0.9 , TLD is not effective in reducing roof displacement. At this low frequency (high period) range, due to low excitation acceleration almost linear single-mode wave formation and weak wave breaking is observed. At high frequency (short period) range, on the other hand, TLD is still effective probably due to high excitation acceleration. At a normalized frequency range of 1.1 to 1.2 , multi-mode wave formation and strong wave breaking are observed.

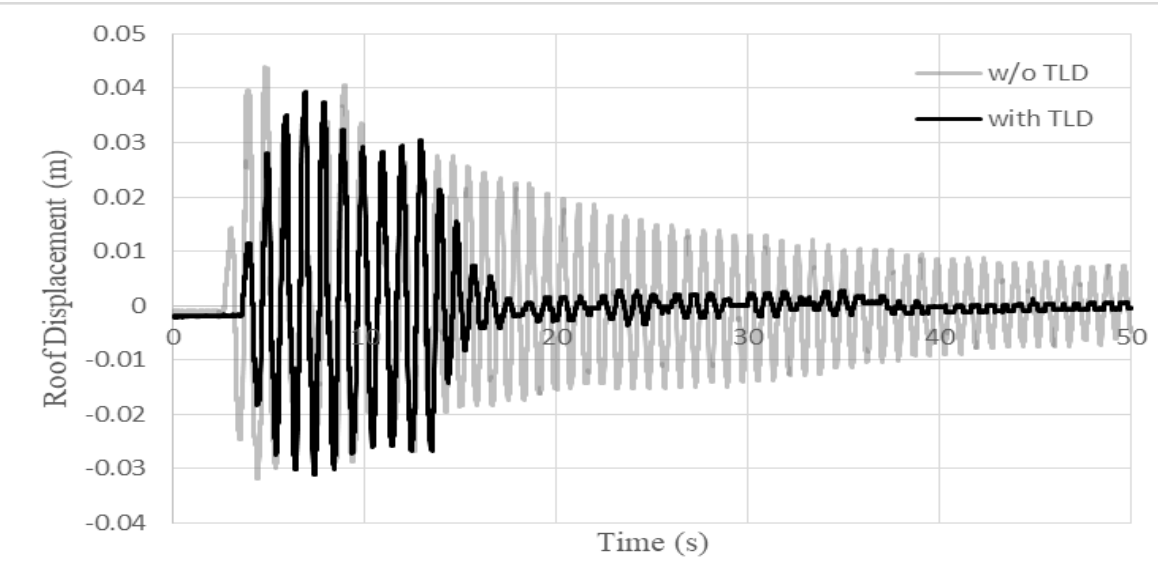

Fig. 3 Displacement Time History, Excitation Frequency is 0.8 Times Fundamental Natural Frequency 


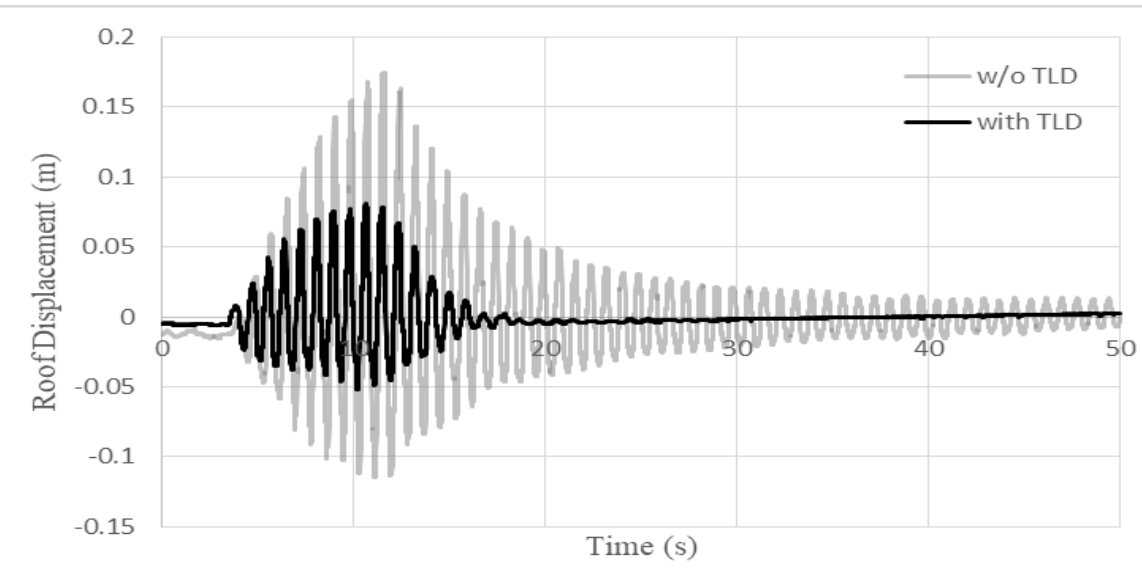

Fig. 4 Displacement Time History, Excitation Frequency is 1.0 Times Fundamental Natural Frequency

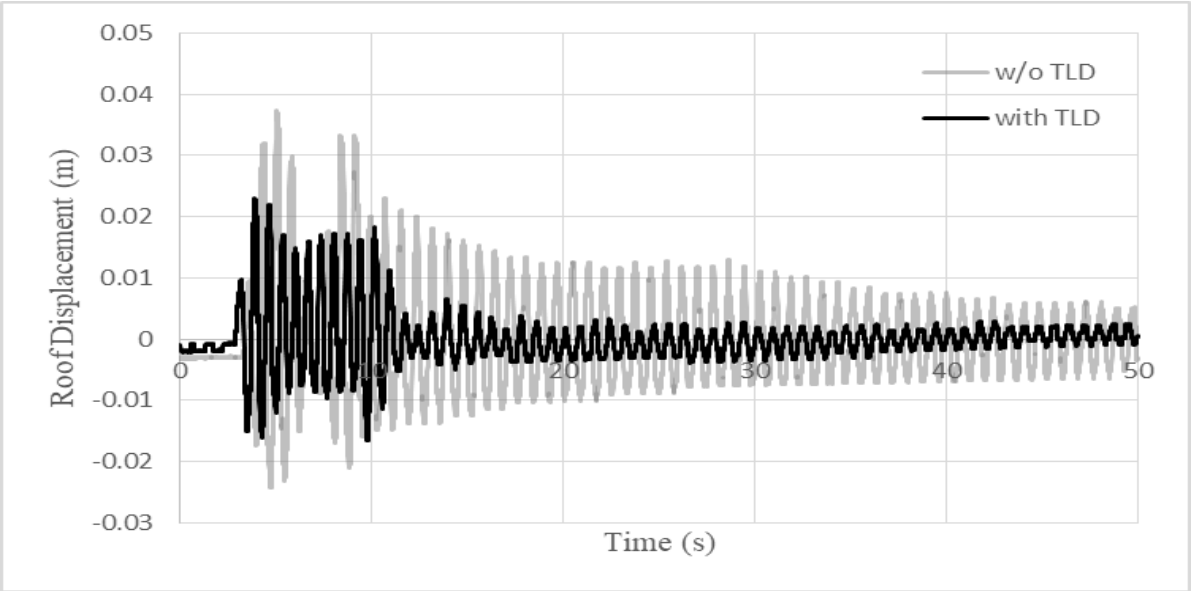

Fig. 5 Displacement Time History, Excitation Frequency is 1.2 Times Fundamental Natural Frequency

As can be seen from Figs. 3-5 the decay of motion of the controlled structure is fast at post excitation stage. The effective damping ratios are calculated to be $7.5 \%, 7.1 \%$, and $11 \%$ corresponding to excitation frequencies of $0.8,1$, and 1.2 times the fundamental frequency of the uncontrolled structure respectively.

\subsection{Response to Earthquake Ground Motions}

Both controlled and uncontrolled structures are tested with different seismic records (Fig. 6) to better evaluate the performance of TLD under earthquake excitation. The seismic records are scaled in order not to exceed the stroke limit of the shake table. Scaling factors are $0.66,1,0.91$, and 0.23 and Peak Ground Acceleration values are $0.218 \mathrm{~g}, 0.367 \mathrm{~g}, 0.315$ $\mathrm{g}$, and $0.144 \mathrm{~g}$ for El Centro, Loma Prieta, Kobe, and Sakarya records respectively. 


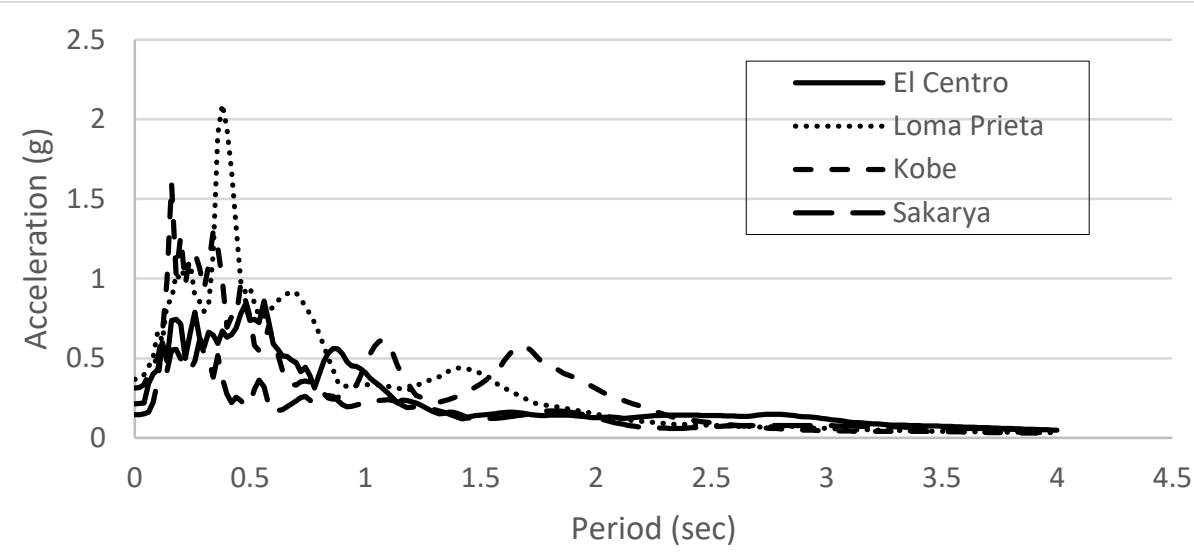

Fig. 6 \%2 Damped Acceleration Response Spectra of Seismic Records

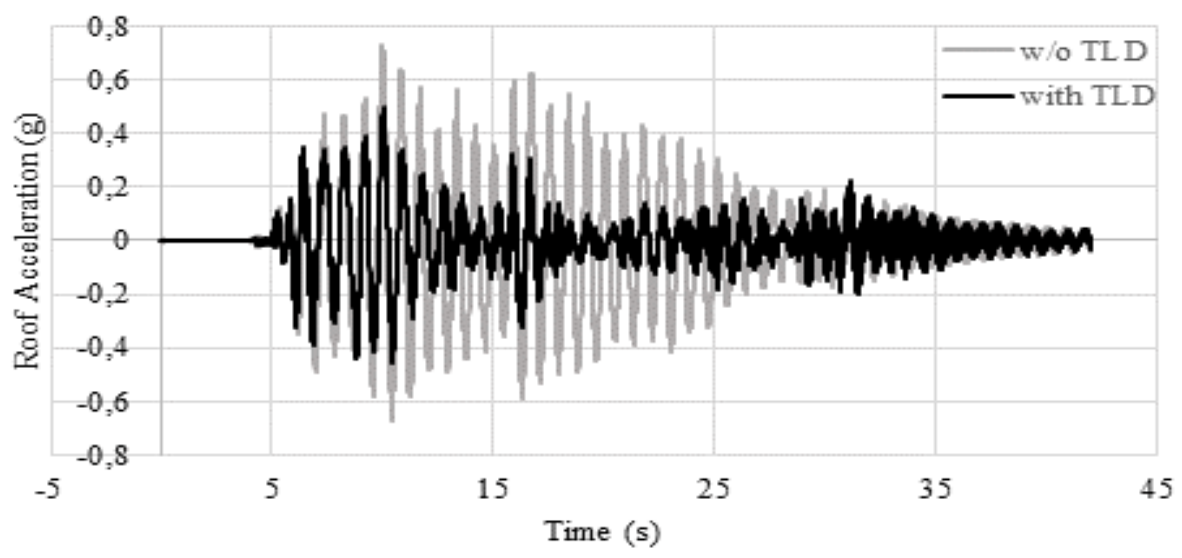

Fig. 7 Acceleration Time History, El Centro Earthquake

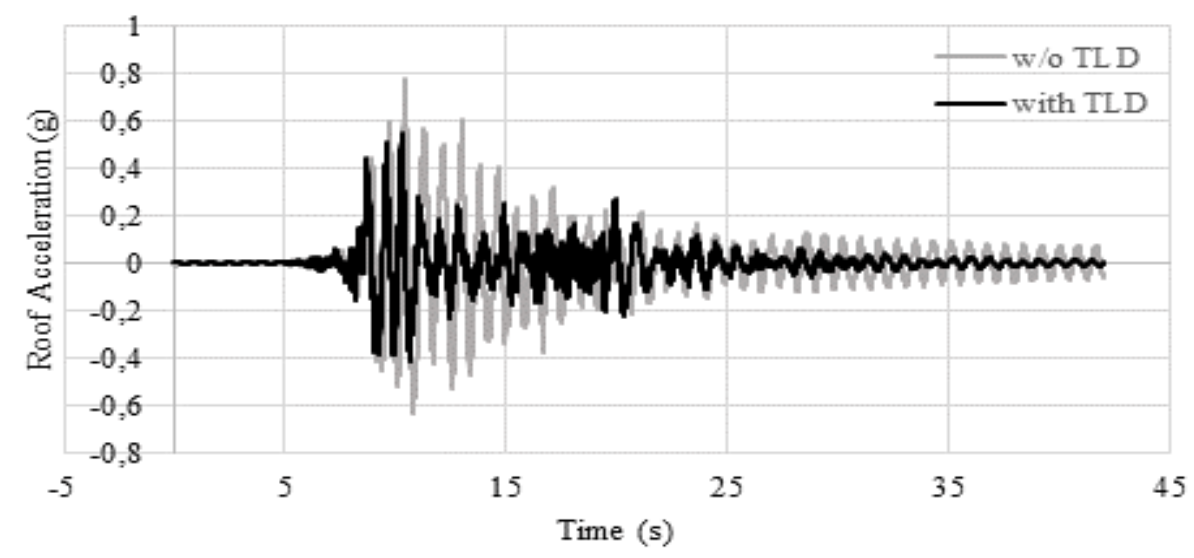

Fig. 8 Acceleration Time History, Kobe Earthquake 


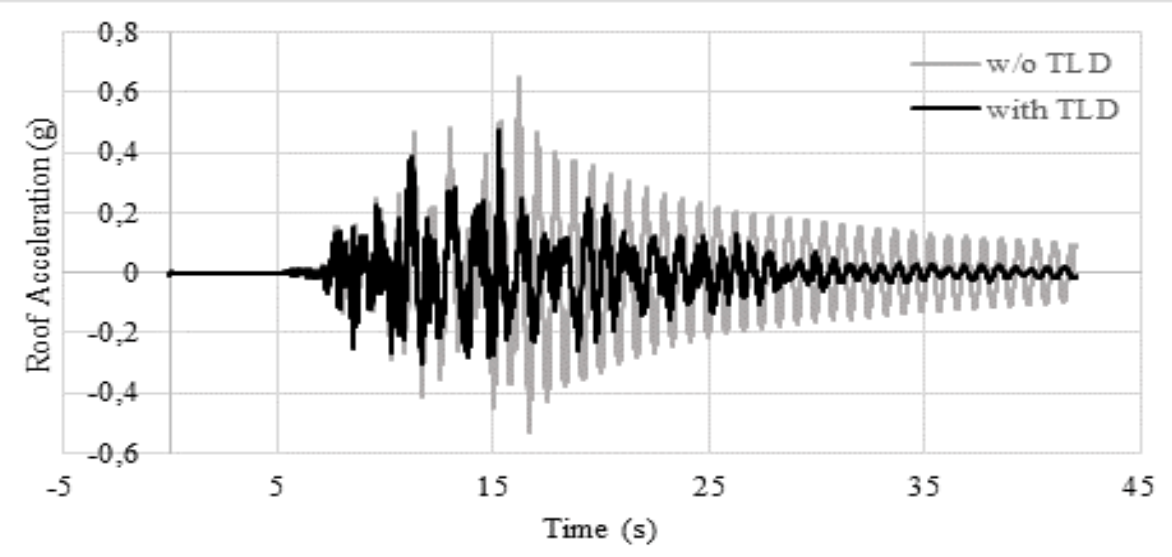

Fig. 9 Acceleration Time History, Loma Prieta Earthquake

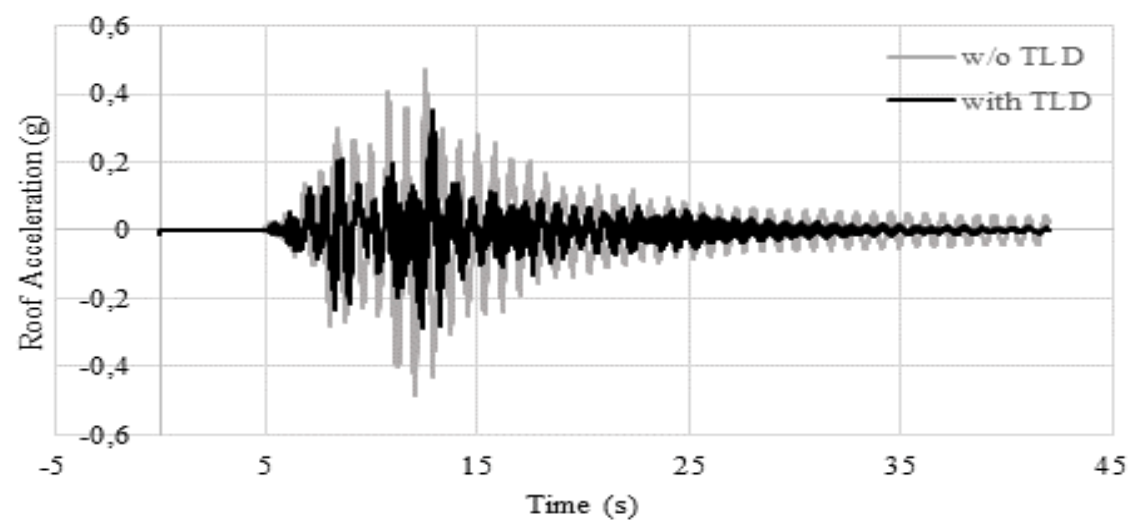

Fig. 10 Acceleration Time History, Sakarya Earthquake

Both controlled and uncontrolled structures are excited with El Centro, Loma Prieta, Kobe, and Sakarya earthquakes and roof accelerations are compared respectively in Figs. 7-10 and Table 1. RMS in Table 1 is the root mean square response of the system and can be interpreted as the energy of the response.

Table 1. Roof Acceleration and RMS comparison

\begin{tabular}{ccccccc}
\hline \multirow{2}{*}{ Record } & \multicolumn{2}{c}{ Roof Acceleration [g] } & \multirow{2}{*}{ Change } & \multicolumn{2}{c}{ RMS (g) } & \multirow{2}{*}{ Change } \\
\cline { 2 - 3 } & w/o TLD & with TLD & (\%) & w/o TLD & with TLD & w) \\
\hline El Centro & 0.73 & 0.49 & 32.01 & 0.218 & 0.107 & 50.92 \\
Loma Prieta & 0.77 & 0.55 & 28.57 & 0.145 & 0.081 & 44.14 \\
Kobe & 0.65 & 0.47 & 27.69 & 0.145 & 0.076 & 47.59 \\
Sakarya & 0.48 & 0.35 & 26.74 & 0.094 & 0.045 & 52.13 \\
\hline
\end{tabular}

It can be seen from Fig. 2 that the natural frequency of the controlled structure is $0,925^{*} 1,234=1.14 \mathrm{~Hz}(\mathrm{~T}=0.88 \mathrm{sec})$. At that period, corresponding spectral accelerations are 0.56 g, 0,35 g , 0.26 g, and 0.23g (Fig. 6) for El Centro, Loma Prieta, Kobe, and Sakarya earthquakes respectively. 
During the tests, it is observed that, when the dominant part of the El Centro and Loma Prieta earthquakes hits the structure, strong wave breaking and multi-mode wave formations occur which are the primary means of energy dissipation in the TLD unit. Although the equivalent mechanical model is not suitable for estimating the complex nature of nonlinear water sloshing, an excessive amount of wave-to-wall interactions seems to dissipate energy especially in the dominant part of ground motion. Thus the change in roof acceleration of the controlled structure with respect to uncontrolled one is relatively higher in these earthquake records. Spectral accelerations corresponding to the dominant vibration period of the controlled structure (Fig. 6) might also be evidence of this since the higher the spectral acceleration, the higher reduction in response is obtained (Table 1).

On the other hand, dissipated energy through the entire time range is best at the Sakarya earthquake which has the lowest spectral acceleration. Due to the low excitation amplitudes of Sakarya and Kobe earthquakes, it is observed weak wave breaking and almost linear sloshing behavior. Thus one possible explanation might be, TLD sloshing dynamics are well estimated by the equivalent mechanical model and optimal solution conditions are met.

\section{Conclusions}

Equivalent mechanical model derivations are based on linear sloshing of water mass, which is possible when the water depth/tank length ratio is high and excitation amplitude is low. On the other hand, when water depth/tank length is low, a larger volume of water sloshes without contributing significantly to the overall inertia of the system which enhances the TLD effectiveness greatly. However, at this point, the nonlinear nature of the sloshing fluid makes it challenging to construct a reliable model. In this study validity of the equivalent mechanical model is investigated when large amplitude vibrations and low water depth/tank length ratios present.

As a primary energy dissipation mechanism, strong wave breaking and wave-to-wall interactions occur at high structural displacements and accelerations. Thus TLD is more effective when the structure is excited with a resonant frequency. In this case reduction in max roof displacement of the controlled (with TLD) structure is $55 \%$ with respect to uncontrolled (without TLD) structure. When the entire frequency range is considered, however, the reduction in max roof displacement of the controlled structure is $37 \%$ with respect to uncontrolled structure. The effectiveness is reduced for low frequency and highfrequency excitations but still, TLD provides a high damping and fast decay of motion when compared to uncontrolled case.

When it comes to seismic excitations, strong vibrations (0.35 -0.55 g accelerations) reason to strong wave breaking and wave-to-wall interactions. Thus dissipated energy is higher leading to better control in max roof acceleration. On the other hand, medium vibrations ( $0.20-0.25$ g accelerations) cause almost linear sloshing behavior so this optimal solution condition leads to better control in total energy of the response.

It can be concluded that a simplified mechanical model can be a good starting point in the optimization of shallow depth TLD. Even if sloshing is not linear thus estimated control parameters varied due to shifting of sloshing frequency, the dissipated energy through nonlinear behavior is satisfactory to enable a sound control.

It seems that inherent damping ratio of the water is underestimated in Eurocode 8 [14] when excitation amplitudes are high. This can be considered in future work. 


\section{Acknowledgement}

The authors acknowledge that this study is supported by TUBITAK (Grant 2209-A 1919B011702712). The author would like to thank Mr. Halil Avcroğlu for his technical assistance during shake table experiments.

\section{References}

[1] Bauer HF, Fluid Oscillations in The Containers of a Space Vehicle and Their Influence upon Stability, Report NASA TR R-187, 1964.

[2] Modi VJ, Welt F. Damping of wind induced oscillations through liquid sloshing, Journal of Wind Engineering and Industrial Aerodynamics, 1988; 30: 85-94. https://doi.org/10.1016/0167-6105(88)90074-8

[3] Fujii K, Tamura Y, Sato T, Wakahara T. Wind-induced vibration of tower and practical applications of Tuned Sloshing Damper, Journal of Wind Engineering and Industrial Aerodynamics, 1990; 33: 263-272. https://doi.org/10.1016/0167-6105(90)90042-B

[4] Kareem A. Reduction of Wind Induced Motion Utilizing a Tuned Sloshing Damper, Journal of Wind Engineering and Industrial Aerodynamics, 1990; 36: 725-737. https://doi.org/10.1016/0167-6105(90)90070-S

[5] Sun LM, Fujino Y, Pacheco BM, Chaiseri P. Modeling of Tuned Liquid Damper (TLD), Journal of Wind Engineering and Industrial Aerodynamics, 1992; 41: 1883-1894. https://doi.org/10.1016/0167-6105(92)90609-E

[6] Wakahara T, Ohyama T, Fujii K. Suppression of Wind-Induced Vibration of a Tall Building using Tuned Liquid Damper, Journal of Wind Engineering and Industrial Aerodynamics, 1992; 41: 1895-1906. https://doi.org/10.1016/0167-6105(92)90610$\underline{\mathrm{M}}$

[7] Koh CG, Mahatma S, Wang CM. Theoretical and experimental studies on rectangular tuned liquid dampers under arbitrary excitations, Earthquake Engineering and Structural Dynamics, 1994; 23: 17-31. https://doi.org/10.1002/eqe.4290230103

[8] Reed DA, Yu J, Yeh H, Gardarsson S. Investigation of tuned liquid dampers under large amplitude excitation, Journal of Engineering Mechanics ASCE, 1998; 124(4): 405-413. https://doi.org/10.1061/(ASCE)0733-9399(1998)124:4(405)

[9] Banerji P, Murudi A, Shah AH, Poppelwell N. Tuned liquid dampers for controlling earthquake response of structures, Journal of Earthquake Engineering and Structural Dynamics, 2000; 29: 587-602. https://doi.org/10.1002/(SICI)10969845(200005)29:5<587::AID-EQE926>3.0.CO;2-I

[10] Tait MJ, Isyumov N, El Damatty AA. Effectiveness of a 2D TLD and its numerical modelling, Journal of Structural Engineering, 2007; 133(2): 251-263. https://doi.org/10.1061/(ASCE)0733-9445(2007)133:2(251)

[11] Malekghasemi H, Ashasi-Sorkhabi A, Ghaemmaghami A, Mercan O. Experimental and numerical investigations of the dynamic interaction of tuned liquid damper-structure systems, Journal of Vibration and Control, 2015; 21(14): 2707-2720. https://doi.org/10.1177/1077546313514759

[12] Pabarja A, Vafaei M, Alih SC, Yatim MY, Osman SA. Experimental study on the efficiency of tuned liquid dampers for vibration mitigation of a vertically irregular structure, Mechanical Systems and Signal Processing, 2019; 114: 84-105. https://doi.org/10.1016/i.ymssp.2018.05.008

[13] Marsh A, Prakash M, Semercigil E, Turan ÖF. A numerical investigation of energy dissipation with a shallow depth sloshing absorber, Applied Mathematical Modelling, 2010; 34: 2941-2957. https://doi.org/10.1016/j.apm.2010.01.004

[14] Eurocode 8, Part 4. Design of Structures for earthquake resistance, Silos, tanks and pipelines, EN 1998-4, 2006. 
[15] Ozsariyildiz SS, Bozer A. Finding optimal parameters of tuned mass dampers, Structural Design of Tall and Special Buildings, 2015; 24(6): 461-475. https://doi.org/10.1002/tal.1174

[16] Love JS, Tait MJ. Parametric depth ratio study on tuned liquid dampers: Fluid modelling and experimental work, Computers and Fluids, 2013; 79: 13-26. https://doi.org/10.1016/j.compfluid.2013.03.004

[17] Housner GW. Dynamic pressure on accelerated containers, Bulletin of the Seismological Society of America, 1957; 47 (1): 15-35.

[18] Karaboga D. An Idea Based On Honey Bee Swarm for Numerical Optimization, Technical Report TR06, Erciyes University, 2015.

[19] Bozer A, Özsarıyıldız SS. Free parameter search of multiple tuned mass dampers by using artificial bee colony algorithm, Structural Control and Health Monitoring, 2018; 25, e2066. https://doi.org/10.1002/stc.2066

[20] Akay B, Karaboga D. A modified Artificial Bee Colony algorithm for real-parameter optimization. Information Sciences, 2012; 192: 120-142. https://doi.org/10.1016/j.ins.2010.07.015

[21] Chopra AK. Dynamics of Structures: Theory and Applications to Earthquake Engineering, 3rd edition Prentice Hall, New Jersey, USA, 2007.

[22] SAP 2000. Structural Software for Analysis and Design, Computers and Structures Inc., Berkeley, USA, 2016. 